\title{
The Important Role of People, Process and Technology during Software Project Requirement
}

\author{
A. Haron, S. Sahibuddin, M. Harun, N. H. Zakaria, and M. N. Mahrin
}

\begin{abstract}
The need of organisation is to enhance the services through Malaysian Public Sector system application. This paper described the role of people, process and technology during software project requirement in Malaysian Public Sector. We have done the survey to the IT Manager in Malaysian Public Sector. The Public Sector IT Manager contributed their working experienced and knowledge for the survey. The purpose of the survey is to determine the $\mathrm{RE}$ practice that implemented during software project requirement. We also determine the role for people, process and technology during the software project requirement. The result shows that 79.7 percent of IT Manager in Malaysia Public Sector has roles in software project requirement such as project leader, project manager and team leader. Some of them have to be a consultant to other agency or organization. They play their roles in business rules, business process indirectly.
\end{abstract}

Index Terms-Requirement engineering, requirement engineering process, SWOT analysis, software project success factor.

\section{INTRODUCTION}

The software project success factor (SPSF) involved during software project development is People, Process, and Technology. Why we need to remind the important of these components? The IT Personnel more often believe they can predict the user needs. They also think that they understand the business well, better than the user, and try to force their ideas on the users [1]. Wherever, the stakeholder always blame that they know what they want through the experience of they manage the business process.

Meanwhile, these groups of people did not realize that sometime the technology has the constraint to fulfill their needs. Analysis may often be carried by IT Personnel without involving people skills and the domain knowledge to understand a client's need. There are; misunderstanding, misalignment and miscommunication will arise during the analysis and negotiation process.

This paper is divided into six sections. The first section comprises this introduction. The second section presents

Manuscript received September 04, 2012; revised November 22, 2012.

A. Haron is with the Public Service Department, Malaysia (e-mail: azlena.haron@yahoo.com).

S. Sahibuddin is with the Advanced Informatics School, Universiti Teknologi Malaysia, Kuala Lumpur, 54100 WP (e-mail: shamsul@utm.my)

M. Harun is with the National Institute of Public Adminstration (INTAN), Public Service Department, Malaysia (e-mail: drmazlan@intanbk.intan.my).

N. H. Zakaria is with the Information System and Computer Science Faculty, Universiti Teknologi Malaysia, Skudai, Johor Bharu, Malaysia (e-mail: hawaniah@utm.my).

M. N. Mahrin is with the Advanced Informatics School, Universiti Teknologi Malaysia, Kuala Lumpur, 54100 WP (e-mail: mdnazrim@utm.my) some software project related work. The third section provides a brief of research method. In fourth section, we presented the finding. In fifth section, we described experimental study that was implemented in Malaysian Public Sector. Finally, the sixth section, we present some conclusion.

\section{RELATED WORK}

The experience on software project development to IT Personnel is increase but still they have not learned enough to ensure that our software development projects are successful. People who involved in setting up the application system have been struggling with how to come up with a highly credible site, and included some comments with regards to sites credibility [5]. The failed projects reviewed were mostly huge and the failure factors were not just management factors but also included technical factors [2]. The technical factor such as software and hardware is to support ICT infrastructure in the organization. Another factor to be considered is IT Personnel that involve in requirement process. The overview knowledge of software engineering is needed to collaborate with many participants from different background [1]. The analysis from the implemented application system in Public Sector can be use as guide. Then alignment the result of analysis with the IT Personnel experienced with Malaysia Public Sector environment.

The first step in developing system is to establish what our stakeholder needs. Bring together all the identified stakeholders; external and internal stakeholder [3]. Then align the needs with the business process to make it as software project requirement. One major problem is the application system did not provide the correct business process as perceived and expected by the users [3]. This is because projects are tracked by monitoring does not consider stakeholder or business process. However, efficient processes are useless if we do not have the right people at the right time. We must consider skills, practices, and organizational characteristic needed to execute the process that will delivers stakeholder needs. Finally, we must have the tools and technologies that support the activities of these people to enable them to achieve their potential an empower them to excel. The key components in these efforts are the focus on upgrading of the use of information and communication technology (ICT) in government agencies to enhance human capital development [6]. The availability of resources with the right competencies helps in implementing the requirement [4].

The outsourcing of software project play different role of the IT Manager. We have to identify the owner of business process, the people will involve, what is their roles, are they 
committed to improving it and working together and important, and are they prepared to do the work to fix the problem. This a good experience and more talented to the IT Personnel.

\section{RESEARCH METHOD}

The implementation of the research base on research problem; the needed of standardized guideline for IT Personnel in Malaysia Public Sector to make sure that the requirement proposed of acceptance for software project requirement practices will align with the Public Sector ICT's Vision. The survey implement in Malaysia Public Sector. The survey answered by the IT Manager as respondent. This group usually had the experience in development or maintenance of software projects. The more senior of their position in organisation, they have more experience in handled a software project such as software development or maintenance, networking, operational and managing data centre. The implementation of research consists of several steps.

The first step is interview with IT Manager that identified have experience in handling software project requirement. The interview guided by a set of questionnaire. The purpose of the interview is to investigate the current RE practices during the preparation of SRS for software project. We determine the main entities and support entities during the SRS process flow. The entities involved are Idea, Initial Requirement, Decision Making, Implementation and Detail Requirement. The SRS process flow supported by Reference, Committee and Guideline entity. This process flow monitoring by appointed people or committee.

The second step is inspections of documents, observations of requirements and policy that can support the research. The objective is related document procedure to support the analysis. Literature related to preparing and development of questionnaire. We identified the software project success factor (SPSF) for Malaysia Public Sector; business rules, business process, technology, stakeholder, developer, and manager [5]. We blend with RE process that identified: elicitation, analysis and negotiation, documentation, and verification and validation [6]. We listed the issues during software project development. We derived RE critical issues from the problem listed by SPSF [7]. We done the mapping of RE process with RE critical issues for developing the RE practice. This set of RE practice is an important part of the survey.

The questionnaire divided into of five parts. The information of IT Manager derived from Part 1. Part 1 is Demographic Profile. The information included their department, organization, gender, education and working experience. Part 2 is Personal Experience in Software Project Requirement. This part is purposely for getting the personnel experienced in the software project requirements. Here, we will know the project involved, who gave the approval, IT Manager position in this project and the length of project to be completed. Part 3 is problems during Software Project Requirement. There happened some problem such as conflict with the roles of manager, stakeholder and developer during software project requirement. In addition, the roles of business rules, business process and technology [5]. Part 4 is investigation on $\mathrm{RE}$ practice during software project requirement. The scale of Part 3 is 1 to 10 , which 1: Not happened at all and 10: Happen all the time. The explicit and implicit RE practice derive from part 4. These parts divided five sections, Elicitation Process, Analysis and Negotiation Process, Documentation Process, Management Process; and Verification and Validation Process [6]. The scale of Part 4 is 1 to 10, which 1: Not implemented at all and 10: Happen all the time. We listed the practice that developed from the RE critical issues in every RE process [7]. For the analysis we divided the scale into 5 groups. The groups are 1-2: Strongly Disagree; 3-4: Medium Disagree; 5-6: Natural Agree; 7-8: Medium Agree; and 9-10: Strongly Agree. Part V is Comments and Suggestions. We used a SPSS to analyses the data.

The third step is a Pilot Test. The suggested practices must also be piloted to ensure the practicality and usefulness of the developed RE process [8]. We tested the RE practice to the selected 25 IT Manager through email. The results show 91.5 percent from the respondent whose response to the survey uses the available methodology to guide them during the requirement process. There are, Waterfall Model, Agile, Incremental, Evolutionary, Prototyping, and Rational Unified Process (RUP). A software lifecycle defines the different stages in the lifetime of a software product. A software lifecycle defines the principles and guidelines with different stages [9]. They used different of methodology because of some reason. There are, type of software project, project leader, duration of the software project, and experience in using the methodology. We developed the RE practice guideline and make it suitable with IT Personnel knowledge and experience. This is the best way for the IT Personnel follow the simple guideline and easy to understand. This guideline blend with the standard suggested.

The fourth step is actual survey. The questionnaire rework based on pilot test comment. The questionnaire survey spread to the respondent $(30 \%$ from the total of IT Manager) in the IT department. Beside to get feedback for the finding, we also want the IT manager aware of the practices that they have done and should be done. The surveys have been distributed to 325 IT Manager to 44 IT agency or IT department in Malaysian Public Sector. The fourth step is conducting the actual survey. The questionnaire used in this step is reworked based on comments received from the pilot test. The new questionnaire is distributed to a total of 325 IT managers and 44 IT agencies in the public sectors. The total respondent is $30 \%$ from the total of IT managers.

The fifth step is evaluation process. The practices will evaluate by the IT expert in Malaysia Public Sector. We identify the expert is the senior IT Personnel (JUSA and above). This group of people is a head of IT Department. They have a lot of experience in managing software project.

Finally, we have to validate the approving requirement of software project with suggested tools. Once the requirements been determined, giving them a weighting. It is for capture the knowledge and experience of experts familiar with the software requirement process. The weights for these factors were determined using expert opinion through the use of a Delphi survey [11]. This testing will produce the best 
practices as an appropriate guideline in developing for software projects in Public Sector.

\section{RESUlT}

We determine software project success factor (SPSF) is Business Rules, Business Process, Technology, Stakeholders Developer, and Managers [7]. Mean while ICT framework act as baseline for the implementation of software project. Every group has their own roles and responsibility. In order to understand their role, we regrouped the SPSF into three component; people, process, and technology (Fig. 1). We analyst the data based on the frequency of respondent.

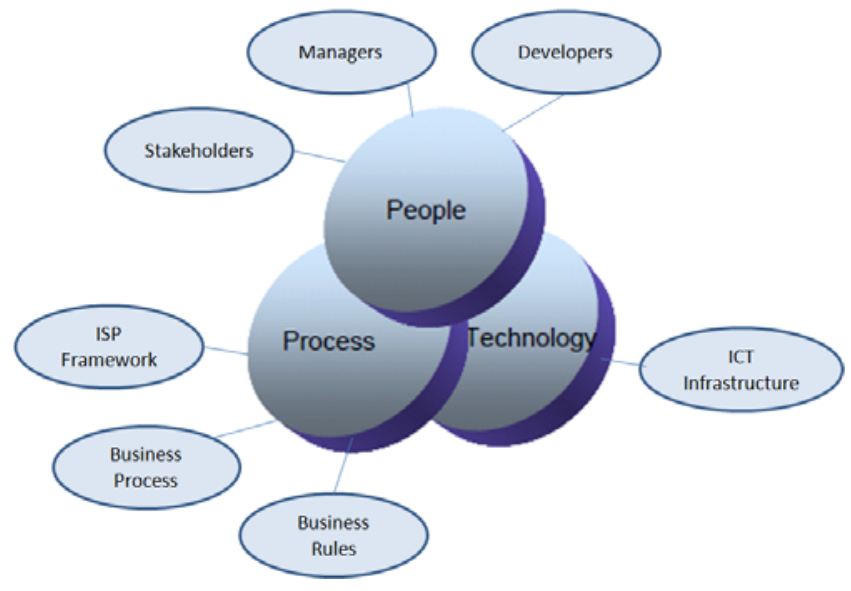

Fig. 1. Software project success factor

SPSF for people are Stakeholders, Developer, and Managers. Top managers and other strategic-view stakeholders agreed that complete and accurate requirements, understanding customer problems and his involvement in the project are necessary for the project success [10]. There are two main knowledge flows: the one from users to developers is mainly knowledge in business domain and other users' tacit knowledge, while the other one from developers to users is knowledge in software domain and system performance requirements, etc [11]. Project managers believe that most important for project success is to have very good project management and experienced team [10] the success of any product depends on the skills and competence of the product manager [12]

SPSF for process are business rules, business process and ISP Framework. Process is a logical sequence of tasks performed to achieve a particular objective [13]. A business rule is a statement that aims to influence or guide behavior and information in an organization and categorized to mandate, policies and guidelines [14]. Ensuring that organizational IT is in alignment with and provides support for an organization's business strategy is critical to business success. A requirements engineering framework for organizational IT directly addresses an organization's business strategy. It will align IT requirements with the business strategy [15]. ISP framework in Malaysian Public Sector contains the ICT Strategic Planning, which directed with vision and mission.

The last SPSF is ICT infrastructure. Technology infrastructure consists of hardware devices, operating systems and middleware on which the information systems run [16].

\section{ANALYSIS}

An analysis done based on people, process and technology. The factor for strength, weaknesses, opportunity and threat shows in Table I, Table II and Table III.

TABLE I: The STRENGTh AND WEAKNESS ANALysis From PEOPLE PERSPECTIVE

\begin{tabular}{cccc}
\hline \hline Strength & Weakness & Opportunity & Threat \\
\hline $\begin{array}{c}\text { Training } \\
\text { Program }\end{array}$ & Technical Skill & $\begin{array}{c}\text { Attachment } \\
\text { Program }\end{array}$ & Management \\
$\begin{array}{c}\text { Business } \\
\text { Process }\end{array}$ & $\begin{array}{c}\text { Business Skill } \\
\text { Movement of } \\
\text { people }\end{array}$ & Certification & Security \\
& Abroad Training & \\
\hline \hline
\end{tabular}

TABLE II: THE STRENGTH AND WEAKNESS ANALYSIS FROM PROCESS PERSPECTIVE

\begin{tabular}{cccc}
\hline \hline Strength & Weakness & Opportunity & Threat \\
\hline Circular & Change Management & Innovation & Restructure \\
Framework & Vision and Mission & Competition & Rebranding \\
Service Delivery & R\&D & & Different \\
e-Government & Awareness & & \\
Expert & & & \\
MAMPU & & & \\
\hline \hline
\end{tabular}

TABLE III: THE STRENGTH AND WEAKNESS ANALYSIS FROM TECHNOLOGY PERSPECTIVE

\begin{tabular}{cccc}
\hline \hline Strength & Weakness & Opportunity & Threat \\
\hline Application systems & RE & Guideline & Tools \\
Workflow and Procedure & REP & R \& D & Techniques \\
Knowledge Capital & Maturity Standard & Consultatio & Methods \\
& RE Maturity & & \\
& ICT Infrastructure & \\
\hline \hline
\end{tabular}

\section{A. The Strength Analysis from People Perspective}

We listed the issues of strength as training program and business process (Table I). National Institute of Public Administration (INTAN) is the training center for Malaysian Public Sector. This training center focus to the public sector business processes. The training program planned to upgrade or refresh the skill and experience of public sector people including IT Personnel. Workers must continuously be trained to enhance their knowledge and skills [17]. INTAN now moves to certification in IT skill such as ITIL, PMP, and CISCO which needed in their daily works. These programs running base on eight fields that IT Personnel in Malaysian Public Sector should be expert. There are, the ICT Strategic Planning, Project Management, Knowledge Management, System Development, Data Center Management, Database Management, Network, and Security. The basic knowledge that IT Manager should have is System Development. The respondent that experiences more than ten years in System Development is 46.2 percent. Software development is a people intensive activity [18]. The more project that the IT manager involve, they have more experience in consult the people to put in practice their responsibility.

We listed the issues of opportunity as local training, attachment program, certification program and abroad training. We make it the issues as our strength to motivate the public sector people. There are many opportunities that given by government in improving skill and knowledge added value for the IT Personnel. The focus is to upgrading of the use of information and communication technology (ICT) in government agencies to enhance human capital development 
[17]. Therefore; Local Training - joint venture with private sector such as IBM, Microsoft; Attachment Program- to other organization for gained experience and knowledge; Certification - further study or joint certified program; and Abroad Training - cooperation or collaboration program with Japan such as JICA, Korea such as KOICA and KOTI, and G15 program. Some of IT Personnel will be given chances in further their study in Master or $\mathrm{PhD}$ program. The frequency of respondent have master degree is 32.5 percent, while 4.3 percent of respondent have $\mathrm{PhD}$. The Public Service Department encourages the IT Personnel to upgrade their knowledge through incentive for Public Sector Personnel (HLP) program. The ICT knowledge that they have during studies can contribute to the improvement of the success of system development. The lack of expert in system development is 41.8 percent happen all the time of the software project requirements. Even though the IT Manager claim they have experience in system development more than ten year, they have experience in manage the software project implementation not the software project requirement.

\section{B. The Weakness Analysis from People Perspective}

We listed the issues of weakness as technical skill, business skill and movement of people (Table I). The needs of technical skill should be align with business skill. The movement of certain people will give impact to development process. Some mechanisms need to be applying in continual by incoming people.

The main need of Public Sector stakeholder is to receive the services on time. They have the high expectation of ICT capability to simplify the business process through the system application. The process for getting requirement from the user is either through the meeting and discussion or through the interview. The user satisfaction of any system filled with basic requirement [19]. The users refer the business process documentation or their work flow for the requirement. The misalignment of requirement with business process is 40.9 percent happen all the time of the software project requirements. The users usually have their own interest and prefer their idea had been accepted. Sometimes the need is base on their feel not base on the business process. The complicated of business process makes the user difficult to understand. The stakeholders also not a technical person, they always change the requirements. The misunderstanding during agreeing process is 50.9 percent happen all the time of the software project requirements. The stakeholder did not understand the development process; the possibilities of changes the requirement and constraints of the ICT technology.

Developer is recognized as technical people. The technical people should have multi skill and knowledge of ICT, with great ideas, creative concepts, and powerful technologies. Surely they can design a great system but it did not mean the application accepted by the stakeholder. The IT people feel the users will need and then try to market the system to the stakeholder. The miscommunication with stakeholder is 50.9 percent happen all the time of the software project requirements. IT people may understand the business process, but their perceptions of the business process objectives may be different with the users. A capable IT Personnel should have a skill set including system development and the business processes, hardware and software technology, able to deal with people, good interviewing and verbal communication skills, conceptual and functional modeling, requirements engineering process and its deliverables, conducting a cost/benefits analysis, issues related to system implementation and organizational change [18]. The lack of soft skill such as communication and negotiation skill is 47.3 percent happen all the time of the software project requirements. IT Personnel need business skill in their communication. The need of negotiation skill and creative thinking can help them during the discussion and understanding process. The difference of background, task and job can creates different vocabularies or terms. The IT Personnel tried to make the requirements fit an existing system rather than develop a system specific to the needs of the client. The business skill that IT Personnel should have is able manage ICT tools, budget estimation, good negotiation and verbal communication skills [18].

Manager can be IT Personnel or non IT Personnel. Project managers believe that most important for project success is to have very good project management and experienced team [10]. Their position during software project requirement is best describes as Project Leader (17.7 percent), Project Manager (25.7) and Team Leader (34.5 percent). Their roles are to make decision of the agreeing that had been decided by stakeholder and developer. One of the most important decisions to be made by a software project manager is how to proper staff the project [19]. What managers thinking is certainly interesting information, but these managers are not the future users. What they want is not necessarily at users want. The conflict with manager is 31.8 percent happen all the time of the software project requirements. The managers probably do not have the kind of knowledge about users needed. The ice breaking program in software project team should include the stakeholder. These programs fit in their planning.

The movement of the IT Personnel is one the important issues. The IT Personnel move because of many reasons such as promotion, inter organization changes or further study. These situations will be affecting the IT Personnel who play the important role in a software development project such as Project Manager, Project Leader and Team Leader. These groups of people are well known with the activities have been planned. They have to transfer their skill, knowledge or expertise to the organization either with documentation or verbally. The best way is through the transfer the technology process.

We listed the issues of threat as management and security. We make it the threat issues as our weakness to encourage the IT Personnel more creative and innovative. Some of the application systems have to be outsourcing to the company. These decisions made of management because of some constraint such as time, expertise and budget. The outsourcing of software project development gave a good change for the IT Personnel in upgrade their knowledge and experience. The warranty period during maintenance with the company should fully used by IT Personnel. Our technical person will do the transfer of technology while they support the maintenance. The critical success factor for Software Company is to respond quickly to changing requirements 
while maintaining but they have the expertise [20]. The outsourcing company more knew the policy, security and workflow. They can guide the IT Personnel during the transfer of technology. The lack of appropriate experience is 42.6 percent happen all the time of the software project requirements. The transfer of technology should be more interesting if the IT Personnel lead in every time of changes, updating and installation. The authorization such as username and password should be given to the Public Sector IT Personnel of the software project.

\section{The Strength Analysis of Process Perspective}

We listed the issues of strength as circular, framework, service delivery, e-Government, expert, MAMPU. MAMPU was given the responsibility of studying and identifying the major problems facing administrative development at all levels of administration and suggesting measures to overcome them (Table II). MAMPU continues to initiate and spearhead administrative improvements and modernization efforts in the public service Government of Malaysia had Circular. Creating a successful application system requires identifying business needs and translating them into a organization vision and scope. Planning the layout of time frame software project is 80.0 percent happen all the time of the software project requirements. Public Sector's ICT Vision is to deliver efficient and quality service through the use of ICT. In achieving this vision, the ICT Strategic Plan will be used in defines the vision, strategic direction and framework for the usage of ICT in the Public Sector; the objectives and strategic thrust areas of ICT development for the Public Sector; as well as the implementation strategies and action plans to be taken to realize the objectives of the plan. The respondent that experience in ICT Strategic Planning is 93.2 percent, and about 23.1 percent of them have experience more than 10 years. It means the Malaysian Public Sector have the experience IT manager that really expert in Strategic Planning which can guide the other in plan the future requirement of ICT. The vision of Malaysia Electronic Government is to transform administrative process and service delivery through the use information communication and multimedia. The implementation of e-Government will gave the good impact in improving the Service Delivery to the public. Designing a credible government application system is a fairly complicated matter. There are group of IT Expertise to be referred in the Malaysia Government.

We listed the issues of opportunity as innovation and competition. There are several ICT competition and ICT innovation in Malaysia Public Sector. This occasion is just not tends for the competition among the agency or organization but more to appreciate and motive the organization in giving best service through ICT.

\section{The Weakness Analysis of Process Perspective}

We listed the issues of weakness as change management, vision and mission, research and development, and awareness (Table 2). IT literate campaign is not for the public, but including the Malaysia Public Sector. One of the major problems due to application system is that the system did not provide the correct business process as perceived and expected by the users. The needs of improvement in their daily work make the high demand of the development of new application system. The constraint of process development system is the capability of IT Personnel. There are more than one of application system should be manage or monitor by the development team. The IT department has to make priority base on the urgency of needs. There are a situation where the system did not use or accept by the user because of the user did not accepted the system. The team has to do awareness programmed to invite the user. Change Management programmed has to be plan and implement. One of the reason is the system did not relate to the vision and mission organization. We should do some research or prototype of the system before we plan to develop the new application system. We can give the best solution for the user and stakeholder.

The dealing with large complex and dynamic projects and processes become a problem with the IT department in the Public Sector. The government plan to outsource in certain IT project to the private sector. The purpose of this programmed is to fill the gap of knowledge and expertise. At the end of project, the training and transfer of technology is a good for win-win situation. But it is not happen because of a gap of communication, knowledge and other factor between public sector and private sector. The practicable schedule should be planning to overcome the issues.

We listed the issues of threat as restructure, rebranding, and different. We make it the issues as our weakness to encourage the IT Personnel more creative and innovative. The structuring of the organization will be affect to software process requirement. Some the IT Personnel will move to other unit or organization. The restructuring of organization is 33.6 percent happen all the time of the software project requirements. The staffing problem is modeled and solved as a constraint satisfaction problem [18]. The ratio of IT Personnel to serve in Malaysia Public Sector in small number compares to other service. The very experienced IT Personnel needed as trainer, consultant and seconded to other organizations. The rebranding will make the IT depart grow with the increase of units and new staff. The organization needs a good plan and time to train the new IT Personnel. The differentiation of business need among organization also give impact to IT Personnel to exchange their experience and knowledge. The different from other Public Sector is a good comparison whereby the government can gets experience or knowledge from other government in the world. The comparison should be base of how to upgrade service delivery with our infrastructure information technology capability. The solutions that base on technology will capable in certain range because of the changes of technology is continual. To fulfil these needs one has to achieve high quality coordination, communication and collaboration. We can use the proof-of-concept in helping the IT Personnel get the idea and best solution. The experience and observation by from the private sector help in reduce the burden on servicing agency, bring in the expertise, enhance the speed of implementation, and offer better value proposition to the citizens.

\section{E. The Strength Analysis of Technology Perspective}

We listed the issues of strength as the needed of application system, workflow and procedure, and knowledge 
capital (Table III). The needed of application systems in automated of business process in improving the service delivery for the stakeholder. The comparison with other country cannot be denied by the government of Malaysia. In the IT era, ICT is the practicable tools to upgrade the services. Workflow and procedure can be improving the current process through the ICT technology. The IT Personnel in Public Service Department is asset to the Public Sector. They have their own skill, knowledge, experience and idea that really different from each others. Their capacity can be categories and level it into the specific goal and also can share through the knowledge sharing. As IT Personnel which tend to be early adopters of new technology, they may not just represent the high technology products. They should be better known as a practitioner and implementing the development of ICT Technology.

We listed the issues of opportunity as guideline, research and development, and consultation. There is several system development models, methodology that can be refer as a guideline. When introducing new technology, government agencies must ensure that the new technology would work well with the existing technology that is already in place [21]. The most important is the IT Personnel should know which model that suitable with the software project. They can base on the research that had been done for the system development by the researcher all over the world. The technology produce as minima globalization is 38.2 percent happen all the time of the software project requirements. They also can base on the company that certified and successful in development and implementation of software projects. They should consider for the solution, less costly business solutions and time to implement. This is particularly attractive when project funding is low or when the delivery schedule is tight.

\section{F. The Weakness Analysis of Technology Perspective}

We listed the issues of weakness as RE, REP, Maturity Standard, RE Maturity, and ICT infrastructure. The ICT skill or knowledge specially focuses to the IT Personal (Table III). The initial requirement which suggested to the management is more to the assumption and experience. Practically, we need to what standard we should refer. Our research to make the implementation or software project requirement realistic with the Public Sector and understood by the IT Personnel. The need of RE basic knowledge is required in helping the IT Personnel know what they should know before jump to the system design. They have to know how to REP process had been done [6]. The difficulty to achieve the international standard is 49.1 percent happen all the time of the software project requirements. This knowledge important either they have to do it on their own or the REP done by the company. They avoid to refer the flow of REP can cause the users not satisfy [4]. The complete of requirement can help the achievable of the maturity of software project. They also need to know the variety of the standard. The IT Personnel should not confuse in using the standard. The constraint of technology is 46.4 percent happen all the time of the software project requirements. The wrong selection of the standard can affect to the end result of software project development. The using of this model is more practical in the Public Sector environment. This model had been implemented the company, the company that involved the Public Sector should used the standard model, and will make the IT Personnel more confident and sure what model that had been used. At the end the IT Personnel should understand the model of RE Maturity.

We listed the issues of threat as tools, technique, and method. We make it the issues as our weakness to encourage the IT Personnel more creative and innovative. The IT Personnel should aware of tools, techniques or methods that they do not understand. The capabilities and limitations of technology must be considered when suggested the software project requirement [13]. The difficulty to explain to stakeholder of the right technology is 44.5 percent happen all the time of the software project requirements. Some of the company just explain the end of the result of the application; they did not show the architecture of the application. At the end IT Personnel cannot customize base on their requirement. There are many types of software engineering: large or small; commodity or custom; embedded or user-intensive; legacy or reuse.

\section{CONCLUSION}

The implementation of software development is a journey or continuing process improvement. The people in the discussion are Stakeholder, Developer and Manager. They are from different background of experience, education, knowledge, needs and goal. The analysis of SPSF will ensure organization achieve their goal and objective. The challenge is to make them agreed on suggested issues. The stakeholder gave the opinion based on their experience in carried out the process. The developer will suggested their experience based on past experience. The manager role should align the idea of stakeholder with the solution suggested by developer. The manager should have or should know the subject matter that discussion between stakeholder and developer.

The changes of business rules and business process should be aware by IT Personnel. Even though we have to limit the changes of requirement but the critical changes should be updated. Otherwise, some may be indicated; the system does not match with workflow; the system is not implemented properly, such as hanging or overload. The most concern is the system is not accepted by the management.

ICT technologies develop rapidly. IT Personnel should always ready to follow the changing needs of application systems. The changes of the system requirements should be studied carefully and accurately. The existing of ICT infrastructure needs to be upgrade accordingly to the requirements. It will avoid from the failure of system implementation. The business process will blend with the technology to fulfill the stakeholder needs and also meet the requirement for Public Sector application system. Meanwhile, the ICT infrastructure is a platform to implement the system application in the organization. No organization can improve all aspects of software project development at once.

As conclusion, the changes in style of work not depend to the system application but more to the people. It wills more effective if the people understand their role and responsibility. The group of people includes Stakeholder, Project Team and Management should understand the process very well before they agree it can be a part of requirement [6]. The IT Personnel usually have to promise or guarantee that the 
system will help the stakeholder improve their daily work. Meanwhile, the stakeholder always not satisfied with the application system. The IT Personnel should aware and know better about the current technology and the appropriate of technology in fulfil the needs of stakeholder and system application. Now that peoples are aligned, and the process developed and clarified, technology can be applied to ensure consistently in application of the process and to provide the guiding to keep the process on track and it easier to follow.

\section{ACKNOWLEDGMENT}

We gratefully acknowledge the funding received from MOHE, Universiti Teknologi Malaysia (UTM) Research Management Centre under Grant 01J19 of Research University Grant and Malaysia Public Service Department.

\section{REFERENCES}

[1] A. Dutoit, R. McCall, I. Mistrík, and B. Paech, "Rationale management in software engineering: Concepts and techniques," Rationale management in software engineering, pp. 1-48, 2006.

[2] N. Cerpa and J. M. Verner, "Why did your project fail?" Communications of the ACM, vol. 52, no. 12, pp. 130-134, 2009.

[3] J. Makolm, "A Holistic Reference Framework for e-Government: The Practical Proof of a Scientific Concept," in System Sciences, 2006. HICSS'06. Proceedings of the 39th Annual Hawaii International Conference on, 2006, vol. 4, p. 77a.

[4] S. Barney, A. Aurum, and C. Wohlin, "Quest for a silver bullet: Creating software product value through requirements selection," in 32nd EUROMICRO Conference onSoftware Engineering and Advanced Applications, 2006, pp. 274-281.

[5] A. Haron and S. Sahibuddin, "The Strength and Weakness of Requirement Engineering (RE) Process," presented at the ICCTD 2010: 2010 the 2nd International Conference on Computer Technology and Development, Cairo, Egypt, 2010.

[6] A. Haron and S. Sahibuddin, "The Roles of an Actor in Requirement Engineering Process," in Proc. of the 3rd IEEE International Conference on Computer Science and Information Technology, Chengdu, China, 2010.

[7] A. Haron and S. Sahibuddin, "Identification of Critical Issues for Requirement Engineering based on Software Project Components in Organisation," in Proc. 2011 International Conference on Software and Information Engineering (ICSIE 2011), Kuala Lumpur, Malaysia, 2011.

[8] M. Kauppinen, M. Vartiainen, J. Kontio, S. Kujala, and R. Sulonen, "Implementing requirements engineering processes throughout organizations: success factors and challenges," Information and Software Technology, vol. 46, no. 14, pp. 937-953, 2004.

[9] A. Fuggetta, "Software process: a roadmap," in Proceedings of the Conference on the Future of Software Engineering, 2000, pp. 25-34.

[10] E. Egorova, M. Torchiano, M. Morisio, C. Wohlin, A. Aurum, and R. B. Svensson, "Stakeholders' Perception of Success: An Empirical Investigation," in Proc. 35th Euromicro Conference on Software Engineering and Advanced Applications, 2009, pp. 210-216.

[11] J. Wan, H. Zhang, D. Wan, and D. Huang, "Research on Knowledge Creation in Software Requirement Development," Journal of Software Engineering and Applications, vol. 3, no. 5, pp. 487-494, 2010.

[12] C. Ebert, "The impacts of software product management," Journal of Systems and Software, vol. 80, no. 6, pp. 850-861, 2007.

[13] J. A. Estefan, "Survey of model-based systems engineering (MBSE) methodologies," Incose MBSE Focus Group, vol. 25, 2007.

[14] M. zur Muehlen, M. Indulska, and G. Kamp, "Business Process and Business Rule Modeling: A Representational Analysis," in Proceedings of the 3rd International Workshop on Vocabularies, Ontologies and Rules for The Enterprise. Eds.: K. Taveter, D. Gasevic. IEEE: Baltimore, Maryland, 2007.

[15] S. J. Bleistein, K. Cox, J. Verner, and K. T. Phalp, "B-SCP: A requirements analysis framework for validating strategic alignment of organizational IT based on strategy, context, and process," Information and Software Technology, vol. 48, no. 9, pp. 846-868, 2006.

[16] R. M. Foorthuis and S. Brinkkemper, "Best Practices for Business and Systems Analysis in Projects Conforming to Enterprise Architecture,"
Enterprise Modelling and Information Systems Architectures, vol. 3, no. 1, pp. 36-47, 2008.

[17] A. M. Azizah and M. Y. Malek Shah, "E- Learning for the Malaysian Public Sector." National Institute of Public Administration (INTAN) Malaysia, 01-Mar-2006.

[18] K. El Emam and N. H. Madhavji, "A field study of requirements engineering practices in information systems development," in Proceedings of the Second IEEE International Symposium on Requirements Engineering, 1995, p. 68.

[19] A. Barreto, M. O. Barros, and C. M. L. Werner, "Staffing a software project: A constraint satisfaction and optimization-based approach," Computers \& Operations Research, vol. 35, no. 10, pp. 3073-3089, 2008.

[20] S. Barney, A. Aurum, and C. Wohlin, "A product management challenge: Creating software product value through requirements selection," Journal of Systems Architecture, vol. 54, no. 6, pp. 576-593, 2008.

[21] M. O. Rosita and M. Nadianatra. E-Recruitment Practice: Pros vs Cons. (2007). [Online]. Available: zotero://attachment/12633/. [Accessed: 04-Nov-2009].

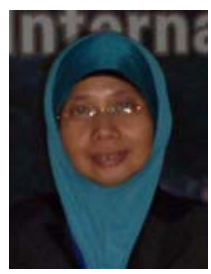

A. Haron is IT Manager in Malaysian Public Sector. She started services with Public Service Department in 1993 as System Analyst. Her experience on developed and managed application system and a trainer for diploma programmed. She also experienced on manage Data Center and Networking. Currently, she is a PhD candidate at the Department of Computer Systems and Communications, Faculty of Computer Science and Information Systems, Universiti Teknologi Malaysia (UTM), Malaysia. Her research interests in requirement engineering.

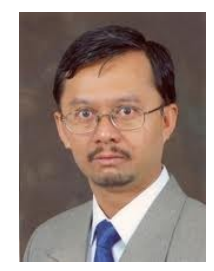

S. Sahibuddin is a professor of the Advanced Informatics School, Universiti Teknologi Malaysia International Campus, Kuala Lumpur, Malaysia. He is also the Dean of Advanced Informatics School. His has produced various publications including journals, papers, monographs, teaching modules and other form of publications. He also joined as a committee member for many conferences and professional membership such as Association of Computing Machinery, ACM SIGGROUP and ACM SIGSOFT to name a few. His research interests are not limited to software engineering, groupware application and software process improvement.

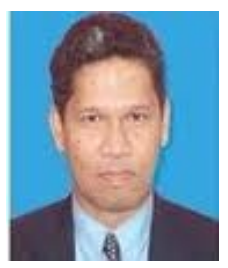

M. Harun is currently the deputy director (ICT) of National Institute of Public Adminstration (INTAN). $\mathrm{He}$ has been involved in Malaysia public sector ICT agenda for over 30 years. He obtained a Ph.D (Computer Science) from the University of Loughborough, United Kingdom in 2000, M.Sc (Computer Science) from University of New York (SUNY), USA in 1991 and B.Sc (Computer Science) from Universiti Sains Malaysia in 1979

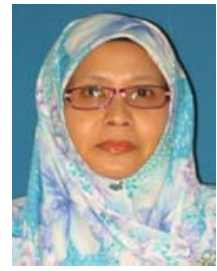

N. H. Zakaria is a senior lecturer at the Faculty of Computer Science and Information Systems, Universiti Teknologi Malaysia, Skudai, Johor Bahru, Malaysia Her research interests are software engineering, database, ontology development, and software process model.

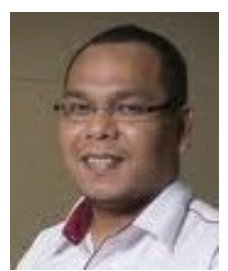

M. N. Mahrim serves as a senior lecturer and IT manager of the Advanced Informatics School, Universiti Teknologi Malaysia International Campus, Kuala Lumpur. He received the BSc and MSc degrees in computer science from the Universiti Teknologi Malaysia in 1997 and 2000 respectively. In 2010, he completed his $\mathrm{PhD}$ degree in Software Engineering from the University of Queensland, Australia. His research interests include software engineering process and quality, software measurement, usability evaluation, and information security management. His current research work (as a project leader) are on test coverage analysis and ontology-based software redocumentation. 